American Journal of Microbiology 2 (1): 9-14, 2011

ISSN 1948-982x

(C) 2011 Science Publications

\title{
Diversity of the Rhizosphere Soil Culture-Dependent Fungi of Mature Tobacco
}

\author{
${ }^{1}$ Xiaolin Li, ${ }^{1}$ Xinzhu Li, ${ }^{1}$ Kewei Zhao, ${ }^{2}$ Ran Wang and ${ }^{1}$ Xiaoping Zhang \\ ${ }^{1}$ Department of Microbiology, College of Resource and Environment, \\ Sichuan Agricultural University, Chengdu 611130, China \\ ${ }^{2}$ Department of Food Science and Engineering, College of Food Science, \\ Sichuan Agricultural University, Yaan 625014, China
}

\begin{abstract}
Problem statement: The maturation of tobacco is a very important period of tobacco production. Until recently, there are no many reports on tobacco rhizospheric culturable fungi, especially at the mature stage. Approach: Five rhizosphere soils of tobacco and five non-rhizosphere soils of tobacco were collected in Yanbian county, Panzhihua. Sixty-one fungal strains isolated from these soil samples were analyzed by $18 \mathrm{~S}$ rDNA PCR-RFLP. And 14 representative strains of them were chosen for $18 \mathrm{~S}$ rDNA sequencing. Results: The results indicated that most of the quantity of fungi of most rhizosphere soils was bigger than rhizosphere's. All strains can be clustered together at similar of $67 \%$ in the analyzing of $18 \mathrm{~S}$ rDNA PCR-RFLP. The strains came from one sample were not always clustered together always, whereas the strains which came from rhizosphere soils or nonrhizosphere soils often clustered together. Conclusion: The results of $18 \mathrm{~S}$ rDNA sequencing showed that dominant fungal species of non-rhizosphere soils were more abundant than rhizosphere. The culture-dependent fungal quantity, community structure and diversity of rhizosphere soil of mature tobacco were affected by the worsening environment of later stage of tobacco.
\end{abstract}

Key words: Mature tobacco, culture-dependent fungi, non-rhizosphere soils, rhizosphere soils, culturable fungi, 18s rDNA sequencing, worsening environment

\section{INTRODUCTION}

The Yanbian county of Sichuan, belonging to south subtropical dry river valley climatic region, has typical characteristics of south subtropical drought and monsoon climate. It has sweltering spring but cool summer, strong sun radiation, plenty of sunshine and more heat, an average annual rainfall $1065.6 \mathrm{~mm}$ and annual mean temperature of $19.2^{\circ} \mathrm{C}$, its advantaged climate resource is very suitable for planting all kinds of flue-cured tobacco.

Plant rhizospheric microorganisms community structure has always been a research hotspot. Many studies showed that the physiological activities of the rhizospheric microorganisms had an important influence on soil properties, nutrient uptake and plant growth and development ( $\mathrm{He}$ and $\mathrm{Li}, 1999)$. The fungus is an important component part of microorganisms and is often closely linked with plant health, even some fungi can directly or indirectly improve the endurance to the poison of heavy metal (Li and Feng, 2001; Wang and Lin, 2007).

Zhang et al. (2009) found that fungus of the tobacco field was the minimum in three bacterium groups, which was similar to the soil microbial distribution in general. Zhan et al. (2005) thought that the quantity of tobacco rhizospheric fungus changed with the growth period of tobacco in same fertile soil. For example, the quantity was on a parabola change in the field of purple soil and yellow soil, at least in the rosette stage, then increasing gradually, reaching the top at budding stage and then to decrease. Meanwhile, Shishido and Chanway (1998) found that, as the harmful metabolism products accumulated, the actinomyces and fungi which had strong resistance increased at later growth stage of plant. Penicillium, Trichoderma, Aspergillus and Fusarium were widely seen as dominant fungi in rhizosphere of field crops (Curl and Truelove, 1986; Gadgil, 1965; Parkinson and Clarke, 1964).

Corresponding Author: Xiaoping Zhang, Department of Microbiology, College of Resource and Environment, Sichuan Agricultural University, Chengdu 611130, China 
In this study, in order to understand the health degree of ecological system in the late period of tobacco and provide certain scientific basis and guidance for the harvest of flue-cured tobacco, the rhizospheric culturable fungi of rhizosphere and nonrhizosphere soils at mature stage had been studied by combining the traditional method with $18 \mathrm{~S}$ rDNA PCRRFLP and sequence analysis.

\section{MATERIALS AND METHODS}

Soil samples: The soil samples were collected from Yanbian county, Sichuan Province where is very suitable for the growth of tobacco. Rhizosphere soil was collected from plants by first removing all visible bulk soil by hand, then the samples consisted of soils from both loosely adhering to roots and that could be brushed or scraped off the root surface (Smalla et al., 2001). The visible bulk soil was collected for nonrhizosphere soil. Fifteen individual healthy plants were collected from every plot. After sampling, the soils were brought to the laboratory and any obvious plant or animal residues were removed by handpicking. Part of the samples were kept with moist in the dark at $4^{\circ} \mathrm{C}$ to assess microbial biomass (Tian et al., 2009).

Enumeration of culturable fungi: Ten grams of each of the soil samples were individually dispensed into 90 $\mathrm{mL}$ of deionised water containing about $20 \mathrm{~g}$ of glass beads ( $3 \mathrm{~mm}$ diameter). Tenfold dilutions were made in sterile deionised water after soil suspensions were centrifuged at $120 \mathrm{r} \mathrm{min}^{-1}$ for $30 \mathrm{~min}$. Then $0.1 \mathrm{~mL}$ aliquots of each soil dilution $\left(10^{-2}-10^{-4}\right)$ were spread on the surface of the different substrates in sterile Petri dishes $(9 \mathrm{~cm}$ diameter). Three plates were used per dilution. The plates were dried in a laminar flow cabinet for $1 \mathrm{~h}$ and then incubated. The CFU of fungi was estimated on Rose Bengal (33 $\mu \mathrm{g} \mathrm{mL}^{-1}$ ) and streptomycin $\left(30 \mu \mathrm{g} \mathrm{mL}^{-1}\right)$ agar on which $100 \mathrm{~mL}$ of 10 -fold serially diluted soil samples were spread. The CFU was counted after incubation for 7 days for fungi at $28^{\circ} \mathrm{C}$ (Kong et al., 2008).

PCR-RFLP of 18S rDNA genes: After collected enough fungal hypha from liquid PDA medium, the genomic DNA extraction was done using procedure described by Yan-Ling et al. (2006). PCR amplification of $18 \mathrm{~S}$ rDNA gene was carried out with primers NS1 (5'-GTAGTCATATGCTTGTCTC-3') and NS4 (5'CTTCCGTCAATTCCTTTAAG-3') (White et al., 1990). The PCR reaction mixture consisted of $25 \mu \mathrm{L}$ $2 \times$ PCR Master mix (Tiangen, Beijing, China. Product components: $0.1 \mathrm{U}$ Taq Polymerase $/ \mu \mathrm{L}, 500 \mu \mathrm{M}$ dNTP each, $20 \mathrm{mM}$ Tris-HCl PH 8.3, $100 \mathrm{mM} \mathrm{KCl}$ and $3 \mathrm{mM}$ $\left.\mathrm{MgCl}_{2}\right), 1.0 \mu \mathrm{L}$ of each primer $\left(20 \mathrm{pmol} \mu \mathrm{L}^{-1}\right), 1.0 \mu \mathrm{L}$ template DNA amount (approximately 1-5 ng) and 22 $\mu \mathrm{L}$ sterile water added to a final volume of $50 \mu \mathrm{L}$. PCR amplification was carried out in BIORAD MyCycler ${ }^{\mathrm{TM}}$, using an initial cycle of denaturation at $94^{\circ} \mathrm{C}$ for $5 \mathrm{~min}$, fourty cycles of denaturation at $94^{\circ} \mathrm{C}$ for $30 \mathrm{sec}$, annealing at $50^{\circ} \mathrm{C}$ for $30 \mathrm{sec}$ and extension at $72^{\circ} \mathrm{C}$ for $1 \mathrm{~min}$; a finial extension cycle at $72^{\circ} \mathrm{C}$ for $6 \mathrm{~min}$. The PCR products were, respectively, digested with restriction endonucleases HaeIII (Bagyalakshmi et al., 2008), HinfI (Helgason et al., 1999), TaqI (Krupa, 1999) and MspI (Mirhendi et al., 2006). The $10 \mu \mathrm{L}$ reactions included $5 \mu \mathrm{L}$ PCR product, $5 \mathrm{U}$ HaeIII/HinfI/TaqI/MspI(Tiangeng, China), $0.2 \mu \mathrm{L}$ $10 \times$ buffer and $7 \mu \mathrm{L} \quad \operatorname{ddH}_{2} \mathrm{O}$. The digestions were performed at $37^{\circ} \mathrm{C}$ for $10 \mathrm{~h}$ (TaqI at $65^{\circ} \mathrm{C}$ ). The digested fragments were separated by gel electrophoresis in $3 \%$ high resolution agarose at $80 \mathrm{~V}$ for $3 \mathrm{~h}$ and visualised with a UV transilluminator. Isolates were grouped based on the combined amplified rDNA restriction analysis patterns using the approaches described by Yuan et al. (2008).

18S rDNA sequencing: According to the results of $18 \mathrm{~S}$ rDNA PCR-RFLP, fourteen representative strains were chosen for $18 \mathrm{~S}$ rDNA gene sequencing carried by Yingjun Biotechnology Ltd. (Shanghai, China). These sequences and their closest match sequences which from GenBank database were pairwise aligned using Clustal X (Thompson et al., 1997). Phylogenetic trees were constructed using the Neighbor-Joining method in MEGA program version 4.0 (Tamura et al., 2007). These sequences were submitted to the GenBank database and the accession numbers were from JN176199 to JN176212.

Statistical analysis: Analysis Of Variance (ANOVA) was conducted on collected data and the mean values of plant fresh weight and disease index were statistically analyzed using the LSD test. Differences were considered to be significant when the probability was less than 0.05 .

\section{RESULTS}

According to the study on morphological observation and preliminary microscopic examination, sixty-one culturable fungi including 32 rhizospheric fungi and 28 non-rhizospheric fungi were selected to analyze with $18 \mathrm{~S}$ rDNA-RFLP (Table 1). 
Am. J. Microbiology 2 (1): 9-14, 2011

Table 1 Fungal strains selected

\begin{tabular}{|c|c|c|c|c|c|}
\hline Strains & Source & Sampling sites & Soil samples & Elevation $(\mathrm{m})$ & Soil type \\
\hline SAUFS1-1,1-2,1-3,1-4,1-5,1-6,1-7 & Rhizosphere & Matang & R1 & 1750 & Purple soil \\
\hline SAUFC1-1,1-2,1-3,1-4,1-5,1-7 & Non-rhizosphere & Matang & NR1 & 1750 & Purple soil \\
\hline SAUFS2-1, 2-2, 2-3, 2-4, 2-5, 2-6 & Rhizosphere & FuxingA & R2 & 1720 & Red soils \\
\hline SAUFC2-1, 2-2, 2-3, 2-4, 2-6 & Non-rhizosphere & FuxingA & NR2 & 1720 & Red soils \\
\hline SAUFS3-1, 3-2, 3-3, 3-4, 3-5, 3-6 & Rhizosphere & FuxingB & R3 & 1680 & Red soils \\
\hline SAUFC3-1, 3-2, 3-3, 3-4, 3-5, 3-6 & Non-rhizosphere & FuxingB & NR3 & 1680 & Red soils \\
\hline SAUFS4-1, 4-2, 4-3, 4-4, 4-5, 4-6 & Rhizosphere & Gude & $\mathrm{R} 4$ & 1730 & Paddy soil \\
\hline SAUFC4-1, 4-2, 4-3, 4-5, 4-6 & Non-rhizosphere & Gude & NR4 & 1730 & Paddy soil \\
\hline SAUFS5-1, 5-2, 5-3, 5-4, 5-5, 5-6 & Rhizosphere & Gaogan & R5 & 1950 & Yellow soils \\
\hline SAUFC5-1, 5-2, 5-3, 5-4, 5-5, 5-6 & Non-rhizosphere & Gaogan & NR5 & 1950 & Yellow soils \\
\hline
\end{tabular}

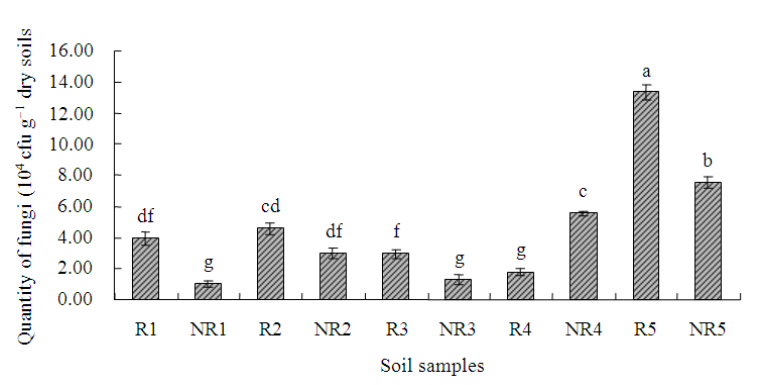

Fig. 1: Quantity of fungi

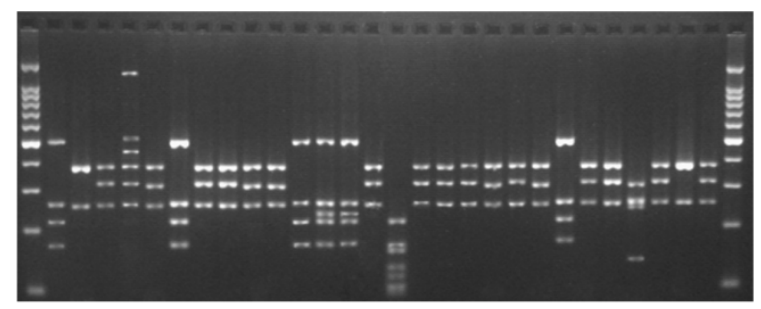

Fig. 2: Restriction patterns of PCR-amplified fragments of $18 \mathrm{~S}$ rDNA digested with HaeIII

Analysis the quantity of fungi: As shown in the Fig. 1, the quantity of fungi among most soils had obvious difference, especially between rhizosphere and nonrhizosphere. In all samples, the largest quantity was in $\mathrm{R} 5$, with $13.33 \times 10^{4} \mathrm{cfu} \mathrm{g}^{-1}$, whereas, the quantity of fungi from NR1 was the minimum, with $1.04 \times 10^{4} \mathrm{cfu}$ $\mathrm{g}^{-1}$. Most of the rhizosphere and its corresponding nonrhizosphere displayed significant difference $(\mathrm{p}<0.05)$ except R2 and NR2. And most of the quantity of culturable fungi of rhizosphere was bigger than rhizosphere's, except R4 and NR4. This may be related to soil types and growth period of tobacco.

Analysis of the 18S rDNA PCR-RFLP: The PCR products of $18 \mathrm{~S}$ rDNA were digested by four restriction enzymes of HinfI, TaqI, HaeIII and MspI. The Fig. 2 showed that the bands of Marker and others were clearly visible and all the 4 restriction endonucleases were suitable to digest the PCR products of $18 \mathrm{~S}$ rDNA.

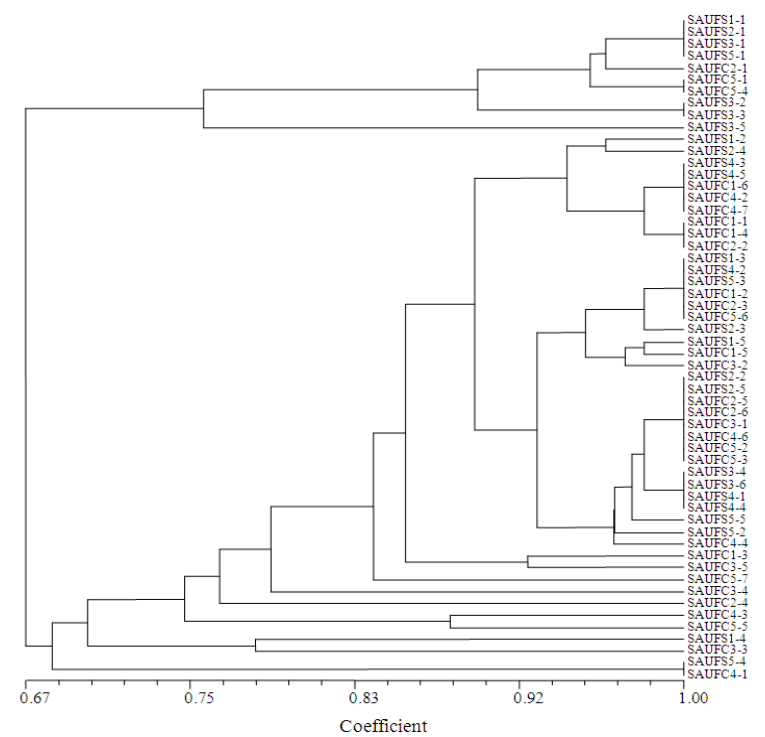

Fig. 3: The dendrogram obtained from 18S rDNA PCRRFLP

Fingerprints of the strains generated by PCR-RFLP of the ribosomal genes were used to construct dendrogram by using UPGMA analysis (Fig. 3). All strains could be clustered together at similar value of $67 \%$ and they would be divided into nine groups at similar value of $83 \%$. Parts of the strains which isolated from one sample were clustered together, such as SAUFC4-2 and SAUFC4-7, SAUFC2-5 and SAUFC2-6. Whereas some were far different, for example, the strains isolated from non-rhizosphere soils in Gude. The strains which isolated from rhizosphere soils often clustered together and the strains isolated from non-rhizosphere soils was same, this showed rhizosphere environment had an influence on the distribution of fungi.

Analysis 18S rDNA sequences: Sixteen representative strains and their closest match sequences which from GenBank database, such as Isaria takamizusanensis, Paecilomyces lilacinus and Gibberella fujikuroi, were selected to make Phylogenetic tree (Fig. 4). 
Am. J. Microbiology 2 (1): 9-14, 2011

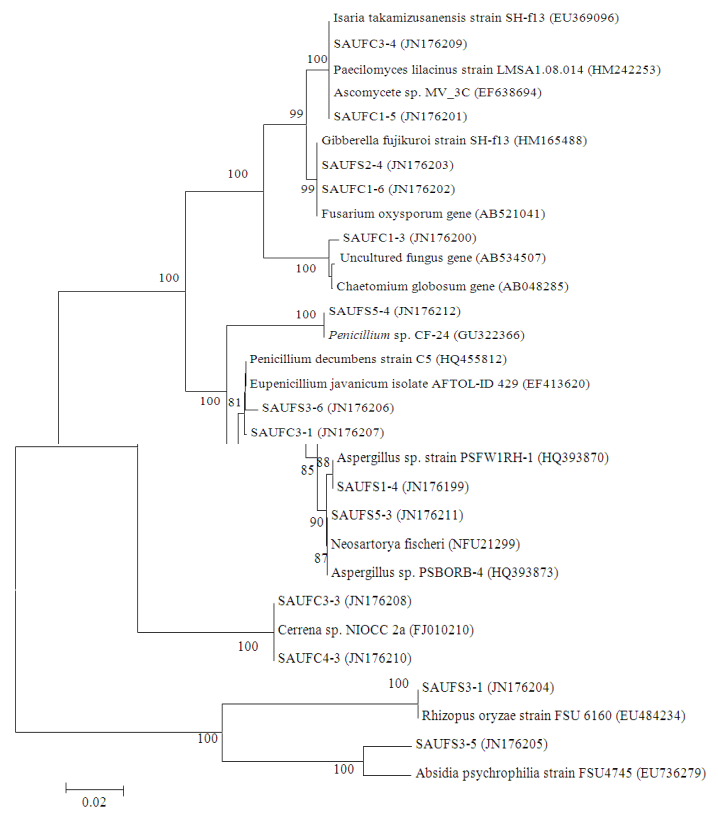

Fig. 4:Dendrogram of actinomycetes strains by Neighbor-joining based on $18 \mathrm{~S}$ rDNA gene sequnences

From homology of the strains tested, the strains involved were very rich and partly reflected the diversity of the culturable fungi. The strain SAUFC3-4 was very similar to Paecilomyces lilacinus strain LMSA1.08.014 (HM242253) isolated from emerald ash borer in Canada (100\% homologous). The strain SAUFC1-5 shared 99\% homology with Ascomycete sp. MV-3C (EF638694) from mid-atlantic ridge and Isaria takamizusanensis strain SH-f13 (EU369096) (Burgaud et al., 2009; Johnson et al., 2009).

The strains SAUFS2-4 and SAUFC1-6 were gathered in a small group. Thereinto, there was $99 \%$ homology between SAUFS2-4 and Gibberella fujikuroi strain SH-f13 (HM165488), SAUFC1-6 was 99\% homologous to Fusarium oxysporum gene (AB521041) (Tagawa et al., 2010). The strain SAUFC1-3 shared 99\% homology with uncultured fungus gene (AB534507) and Chaetomium globosum gene (AB048285) (Hoshino and Morimoto, 2010). The strain SAUFS5-4 was similar to Penicillium sp. CF-24 (GU322366) in the extent of 99\%. In addition, SAUFS3-6 isolated rhizosphere soil R3 was very similar to SAUFC3-1 isolated non-rhizosphere soil NR3.

There was $100 \%$ homology between SAUFS3-6 and Penicillium decumbens strain C5 (HQ455812) and 99\% homology between SAUFC3-1 and Eupenicillium javanicum isolate AFTOL-ID 429 (EF413620) (Geiser et al., 2006). Meanwhile, SAUFS1-4 was highly homologous to Aspergillus sp. strain PSFW1RH-1 (HQ393870) and when SAUFS5-3 was homologous to Aspergillus sp., it was also very similar to Neosartorya fischeri (NFU21299). SAUFC3-3 and SAUFC4-3 both isolated from non-rhizosphere soil were homologous to Cerrena sp. NIOCC 2a (FJ010210) (99 and 100\%, respectively). SAUFS3-1 and SAUFS3-5 that were difference with other strains tested gathered in a group, the former had high homology with Rhizopus oryzae strain FSU 6160 (EU484234) and the latter was very similar to Absidia psychrophilia strain FSU4745 (EU736279).

\section{DISCUSSION}

In general, tobacco rhizospheric exudations in different growth periods have influence on the quantity of fungi. The quantity of culturable fungi of rhizosphere was more than non-rhizosphere's in most of samples except Fuxing A and Gude. The quantity of fungi of R2 hadn't significant difference with NR2 ( $>>0.05)$. The quantity of fungi of non-rhizosphere of Gude site was more than rhizosphere's (NR5>R5).

From the representative strains reflected, the dominant fungal species in tobacco rhizosphere soil were Aspergillus sp., Gibberella fujikuroi, Rhizopus oryzae, Absidia psychrophilia, Penicillium decumbens and Neosartorya fischeri. Whereas, in tobacco nonrhizosphere soil were Aspergillus sp., Chaetomium globosum, Ascomycete sp., Fusarium oxysporum, Eupenicillium javanicum, Paecilomyces lilacinus, Penicillium sp. and Cerrena sp..

English and Mitchell (1988) found that Penicillium, Trichoderma, Aspergillus and Fusarium grew quickly in tobacco rhizosphere soil. However, Trichoderma, Aspergillus and Fusarium hadn't been found in dominant fungal species in tobacco rhizosphere soils in our study. On the contrary, Aspergillus and Fusarium appeared in the nonrhizosphere soils. Gibberella fujikuroi is pathogenic fungi of rice bakanaea disease in rhizosphere soil, although it has little effect on tobacco, it not only can infect non-crop Fistula arundinaceous, Leerier sayanuka Ohwi and Digit aria sanguinely (L.) Scoop. But also can infect field plants, such as wheat, sorghum, maize, etc. Gibberella fujikuroi became a dominant fungal species at later growth stage of tobacco may be related to the current degradation of tobacco rhizospheric environment. Compared with nonrhizosphere, Neosartorya fischeri which has antiinflammatory action was found in dominant fungal species of rhizosphere. 
Am. J. Microbiology 2 (1): 9-14, 2011

\section{ACKNOWLEDGEMENT}

The researchers are grateful to an anonymous reviewer for kindly correcting this manuscript. This work was supported by the Chinese National Natural Science Fund (No. 31070004) and the specialized research found for the doctoral program of higher education 20060626006.

\section{CONCLUSION}

The quantity of fungi and population of tobacco rhizosphere soil at later growth stage were different with non-rhizosphere soil, especially the population, which was influenced by the degradation of rhizosphere environment. If the environment aggravates to a definite level, tobacco diseases may occur and lead to yield reduction. It is not suitable to control tobacco diseases using pesticide at maturity stage. In order to obtain high yield at later growth stage, we should improve the field ventilated condition, reduce the field temperature properly, clean diseased leaves and disabled body timely and bake at the right time, except for selecting resistant varieties with local conditions.

\section{REFERENCES}

Bagyalakshmi, R., B. Senthilvelan, K.L. Therese and H.N. Madhavan, 2008. Application of Polymerase Chain Reaction (PCR) and PCR based restriction fragment length polymorphism for detection and identification of dermatophytes from dermatological specimens. Indian J. Dermatol., 53: 15-20. DOI: 10.4103/0019-5154.39735

Burgaud, G., T.L. Calvez, D. Arzur, P. Vandenkoornhuyse and G. Barbier, 2009. Diversity of culturable marine filamentous fungi from deepsea hydrothermal vents. Environ. Microbiol., 11: 1588-1600. DOI: $\quad 10.1111 / \mathrm{j} .1462-$ 2920.2009.01886.x

Curl, E.A. and B. Truelove, 1986. The Rhizosphere. 1st Edn., Springer Verlag, Berlin, ISBN: 9780387158037, pp: 288.

English, J.T. and D.J. Mitchell, 1988. Development of microbial communities associated with tobacco root systems. Soil Biol. Biochem., 20: 137-144. DOI: 10.1016/0038-0717(88)90029-6

Gadgil, P.D., 1965. Distribution of fungi on living roots of certain Gramineae and the effect of root decomposition on soil structure. Plant Soil, 22: 239-259. DOI: 10.1007/BF01373995

Geiser, D.M., C. Gueidan, J. Miadlikowska, F. Lutzoni and F. Kauff et al., 2006. Eurotiomycetes: eurotiomycetidae and chaetothyriomycetidae.
Mycologia, 98: 1053-1064. DOI: 10.3852/mycologia.98.6.1053

He, X.L. and B. Li, 1999. Selection research of VA mycorrhizal fungus and plant. Acta Bot Bor-Occid Sin, 19: 471-475.

Helgason, T., A.H. Fitter and J.P. Young, 1999. Molecular diversity of arbuscular mycorrhizal fungi colonising Hyacinthoides non-scripta (bluebell) in a seminatural woodland. Mol. Ecol., 8: 659-666. DOI: $10.1046 /$ j.1365294x.1999.00604.X

Hoshino, Y.T. and S. Morimoto, 2010. Soil clone library analyses to evaluate specificity and selectivity of PCR primers targeting fungal 18S rDNA for Denaturing-Gradient Gel Electrophoresis (DGGE). Microb. Environ., 25: 281-287. DOI: 10.1264/jsme2.ME10136

Johnson, D., G.H. Sung, N.L. Hywel-Jones, J.J. Luangsa-Ard and J.F. Bischoff et al., 2009. Systematics and evolution of the genus torrubiella (Hypocreales, Ascomycota). Mycol. Res., 113: 279-289. DOI: 10.1016/j.mycres.2008.09.008

Kong, C.H., P. Wang, H. Zhao, X.H. Xu and Y.D. Zhu, 2008. Impact of allelochemical exuded from allelopathic rice on soil microbial community. Soil Biol. Biochem., 40: 1862-1869. DOI: 10.1016/j.soilbio.2008.03.009

Krupa, P., 1999. Identification by PCR-RFLP of a fungus isolated from mycorrhizal roots of a distinguishable birch growing in areas disturbed by industry. Polish J. Environ. Stud., 8: 161-163.

Li, X.L. and G. Feng, 2001. Arbuscular Mycorrhizal Ecophysiology. Huawen Publishing House, Beijing, ISBN: 7507511782, 9787507511789, pp: 358.

Mirhendi, H., K. Makimura, M. Khoramizadeh and H. Yamaguchi, 2006. A one-enzyme PCR-RFLP assay for identification of six medically important Candida species. Jpn. J. Med. Mycol., 47: 225229.

Parkinson, D. and J.H. Clarke, 1964. Studies on fungi in the root region. III. Root surface fungi of three species of Allium. Plant Soil, 20: 166-174. DOI: 10.1007/BF01376446

Shishido, M. and C.P. Chanway, 1998. Forest soil community responses to plant growth-promoting rhizobacteria and spruce seedlings. Biol. Fert. Soils, 26: 179-186. DOI: 10.1007/s003740050365

Smalla, K., G. Wieland, A. Buchner, A. Zock and J. Parzy et al., 2001. Bulk and rhizosphere soil bacterial communities studied by denaturing gradient gel electrophoresis: Plant-dependent enrichment and seasonal shifts revealed. Applied Environ. Microbiol., 67: 4742-4751. PMID: 11571180 
Tagawa, M., H. Tamaki, A. Manome, O. Koyama and Y. Kamagata, 2010. Isolation and characterization of antagonistic fungi against potato scab pathogens from potato field soils. FEMS Microbiol. Lett., 305: $\quad 136-142 . \quad$ DOI: $10.1111 / \mathrm{j} .1574-$ 6968.2010.01928.x

Tamura, K., J. Dudley, M. Nei and S. Kumar, 2007. MEGA4: Molecular Evolutionary Genetics Analysis (MEGA) software version 4.0. Mol. Biol. Evol., $\quad 24: \quad 1596-1599 . \quad$ DOI: 10.1093/molbev/msm092

Thompson, J.D., T.J. Gibson, F. Plewniak, F. Jeanmougin and D.G. Higgins, 1997. The CLUSTAL_X windows interface: Flexible strategies for multiple sequence alignment aided by quality analysis tools. Nucl. Acids Res., 25: 48764882. DOI: $10.1093 / \mathrm{nar} / 25.24 .4876$

Tian, F., Y.Q. Ding, H. Zhu, L.T. Yao and B.H. Du, 2009. Genetic diversity of siderophore-producing bacteria of tobacco rhizosphere. Braz. J. Microbiol., 40: 276-284.

Wang, F.Y. and X.G. Lin, 2007. Role of a buscular mycorrhizae in phytoremediation of heavy metalcontaminated soils. Acta Ecol. Sinica, 27: 793-801.
White, T.J., T. Bruns, S. Lee and J. Taylor, 1990. Amplification and direct sequencing of fungal ribosomal RNA genes for phylogenetics. Academic Press, New York, pp: 315-322.

Yuan, H., X. Zhang, K. Zhao, K. Zhong and Y. Gu et al., 2008. Genetic characterisation of endophytic actinobacteria isolated from the medicinal plants in Sichuan. Ann. Microbiol., 58: 1-8. DOI: 10.1007/BF03175563

Zhan, F.D., Y.G. Lu, G.J. Guan, Y.J. Tang and Y.C. Zhang et al., 2005. Community structures of microorganisms and their dynamics in the rhizosphere of flue-cured tobacco. Acta. Pedologica. Sinica., 42: 488-493.

Zhang, H.Y., C.H. Wang, M.F. Gong and L. Zhang, 2009. A simple and effective method of DNA extraction from soil for molecular biodiversity analysis. Biotech. Bull., 8: 151-155.

Yan-Ling, Z., C. Xian-Jie and W. Xin-Min, 2006. Microbe composition and vertical distribution profile in tobacco growing soil. Tobacco Sci. Technol., 9: 61-64. 